\title{
Kinetics and Mechanism of Solid State Reactions in the AgI-TlI System
}

\author{
Giorgio Flor, Vincenzo Massarotti and Riccardo Riccardi \\ Centro di studio per la termodinamica ed elettrochimica dei sistemi salini fusi e solidi del C. N. R. \\ Institute of Physical Chemistry, University of Pavia (Italy) \\ (Z. Naturforsch. 30 a, 304-307 [1975] ; received January 6, 1975)
}

The kinetics of the solid state reactions

$$
\begin{aligned}
\mathrm{AgI}+\mathrm{TII} & \rightarrow \mathrm{AgTlI}_{2} \\
\mathrm{AgI}+\mathrm{AgTl}_{2} \mathrm{I}_{3} & \rightarrow 2 \mathrm{AgTlI}_{2} \\
\mathrm{AgTII}_{2}+\mathrm{TlI} & \rightarrow \mathrm{AgTl}_{2} \mathrm{I}_{3}
\end{aligned}
$$

are investigated with reactant pellets by the contact method.

With the aid of inert marker experiments and transport number determinations it was possible to state that the governing mechanism is the cation counter-diffusion in all cases and that the rate determining step is the diffusion of $\mathrm{Tl}^{+}$.

The experimental reaction rate constants agree reasonably with those calculated on the basis of the Wagner's thermodynamic theory.

\section{Introduction}

The solid state reactions between AgI and univalent cation iodides yield compounds with relatively high (in some cases very high) values of the electrical conductivity ${ }^{1}$. From electrical conductivity and transport number measurements it is rather easy to determine the mobility of the component species for these compounds and thus to evaluate the rate-determining step.

Up to date the kinetics of these reactions have been studied for the AgI- $(\mathrm{K}, \mathrm{Rb}) \mathrm{I}$ system only ${ }^{2}$. In the present work the results obtained in a kinetic study of the AgI-TII system are reported.

The relevant phase diagram shows two different compounds: $\mathrm{AgTlI}_{2}$ which melts incongruently at $240{ }^{\circ} \mathrm{C}$ and $\mathrm{AgTl}_{2} \mathrm{I}_{3}$ which melts congruently at $327^{\circ} \mathrm{C}^{3}$. Therefore, the kinetics was investigated for the formation reactions of $\mathrm{AgTlI}_{2}$ and $\mathrm{AgTl}_{2} \mathrm{I}_{3}$ from $\alpha-\mathrm{AgI}+\alpha$ - or $\beta$-TII ( $\alpha$-AgI, stable form between $147^{\circ} \mathrm{C}$ and $\mathrm{mp} ; T_{a, \beta}$ of $\mathrm{TlI}=170^{\circ} \mathrm{C} 4,5$ ) in the temperature range $150.5-197^{\circ} \mathrm{C}, \mathrm{AgTlI}_{2}$ from $\alpha-\mathrm{AgI}+\mathrm{AgTl}_{2} \mathrm{I}_{3}$ at $180^{\circ} \mathrm{C}$ and $\mathrm{AgTl}_{2} \mathrm{I}_{3}$ from $\mathrm{AgTlI}_{2}$ $+\alpha$-TII at $180^{\circ} \mathrm{C}$. Couples of reagent pellets were used and the thickness of the product formed was measured by optical microscopy.

Reprint requests to Prof. Riccardo Riccardi, Istituto di Chimica Fisica Università di Pavia, 1-27100 Pavia (Italy).
Moreover, in order to obtain information on the reaction mechanism, the inert marker method was used.

Finally, the measured rate constants were compared with those calculated on the basis of the Schmalzried equation ${ }^{6}$ employing the transport number of $\mathrm{Tl}^{+}$and the electrical conductivity values as determined on $\mathrm{AgTlI}_{2}$ and $\mathrm{AgTl}_{2} \mathrm{I}_{3}$.

\section{Experimental}

Fluka "puriss." AgI and TlI were used. $\mathrm{AgTlI}_{2}$ and $\mathrm{AgTl}_{2} \mathrm{I}_{3}$ were prepared by melting under nitrogen AgI + TlI mixtures of proper composition, by quenching in liquid nitrogen and then annealing for $150 \mathrm{~h}$ at 215 and $300{ }^{\circ} \mathrm{C}$ respectively. The products so obtained were powdered, pelletized and again annealed at the same temperatures. The completion of compound formation was confirmed by X-ray, DSC and especially electrical conductivity measurements ${ }^{7}$.

All the products were used in form of pellets ( $8 \mathrm{~mm}$ wide and $\sim 1.5 \mathrm{~mm}$ thick) obtained by pressing the powders at $1.5 \cdot 10^{3} \mathrm{~kg} / \mathrm{cm}^{2}$.

The apparatus employed for the rate measurements has been previously described ${ }^{8}$. Transport number determinations on $\mathrm{AgTlI}_{2}$ and $\mathrm{AgTl}_{2} \mathrm{I}_{3}$ were carried out by the Tubandt method using as source of constant d.c. an Amel mod. 551 galvanostat. Conductometric data were obtained by a Wayne Kerr autobalance bridge B 331. 


\section{Results and Discussion}

a) Kinetics Measurements

(I) Reaction AgI + TlI. From marker (Pt wires) experiments on the diffusion couples AgI $\mid$ TlI kept at $180^{\circ} \mathrm{C}$ for $120 \mathrm{~h}$ it was observed that the marker is located in the middle of a homogeneous deep yellow product layer, $350 \mu \mathrm{m}$ thick. $\mathrm{X}$-ray analysis on the finely powdered product exhibited only the reflections of $\mathrm{AgTlI}_{2}{ }^{9}$, whereas some of the most intense reflections of $\mathrm{AgTl}_{2} \mathrm{I}_{3}$ could only be brought into evidence by X-ray analysis of the product surface in contact with TII. It can be deduced that the thickness of this product layer is very small, anyhow lower than the minimum observable under the microscope.

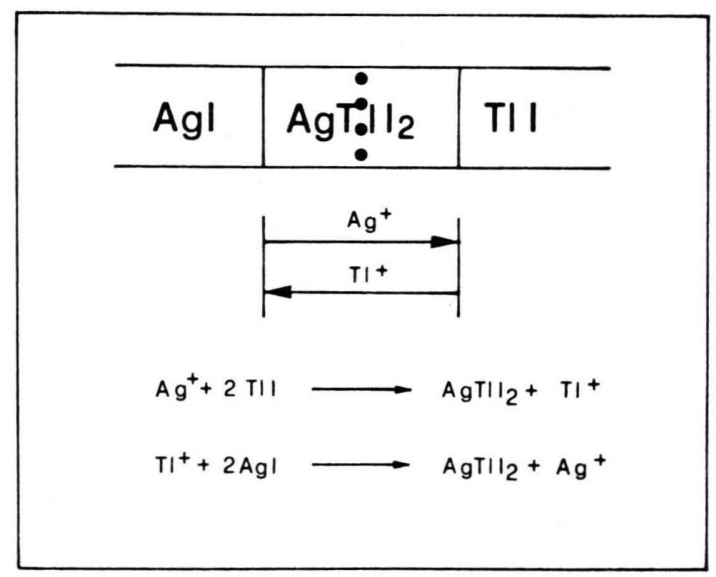

Fig. 1. Scheme for reaction (I) mechanism.

Figure 1 (where the marker position is indicated by dots) shows that the process mechanism is a cation counter-diffusion.

Strictly similar results were obtained at $160^{\circ} \mathrm{C}$, TlI being in the $\beta$ form.

Fairly good linear plots of $x^{2} \quad(x=$ average thickness of the product layer as measured by the microscope) vs. $t$ are obtained as reported in Figure 2. The process follows the parabolic law ${ }^{10}$

$$
x^{2}=2 k v t
$$

where $k$ is the reaction rate constant and $v$, which is the volume increase of the reaction layer caused by transfer of one equivalent, takes different values according to the reaction mechanism (for $\mathrm{AgTlI}_{2}$ formation, in this case, $v=160 \mathrm{~cm}^{3} / \mathrm{eq}$ ).

The Arrhenius plot shown in Fig. 3 is characterized by two straight lines fitted by the equations

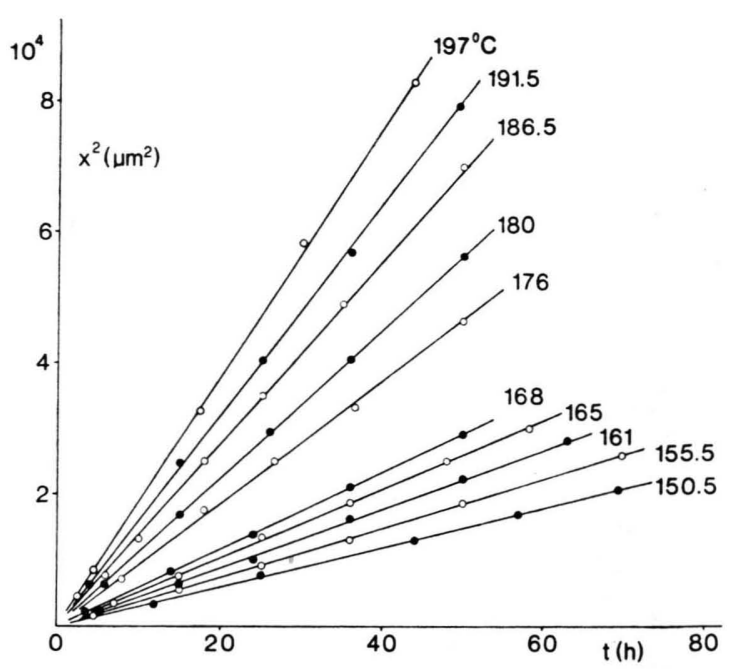

Fig. 2. Isotherms for reaction (I).

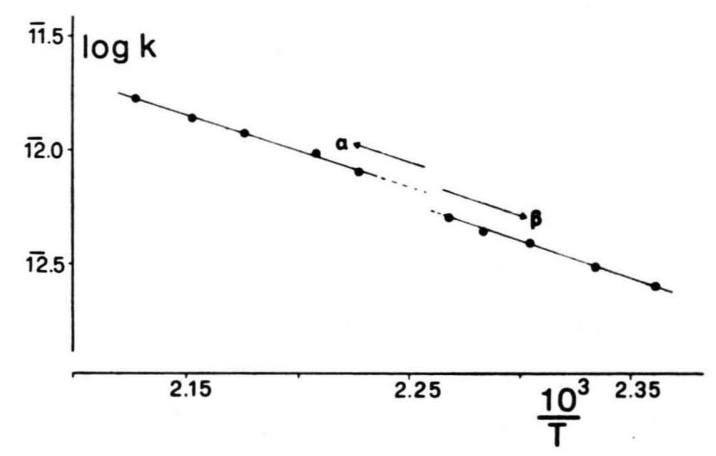

Fig. 3. Arrhenius plot for reaction (I).

$\left(150.5-168{ }^{\circ} \mathrm{C}\right) \log k=-4.05-14,622 / 4.576 T$,

$\left(176-197^{\circ} \mathrm{C}\right) \quad \log k=-4.06-14,439 / 4.576 T$

where $k$ is expressed in eq $\mathrm{cm}^{-1} \mathrm{sec}^{-1}$.

(II) Reaction AgI $+\operatorname{AgTl}_{2} \mathrm{I}_{3}$. Marker experiments at $180^{\circ} \mathrm{C}$ for $120 \mathrm{~h}$ on the diffusion couples $\mathrm{AgI} \mid \mathrm{AgTl}_{2} \mathrm{I}_{3}$ showed that the marker position divided the formed $\mathrm{AgTlI}_{2}$ layer $(360 \mu \mathrm{m})$ in a $1: 3$ ratio. It follows that the reaction is governed by the cation counter-diffusion mechanism shown in Figure 4.

Measurements of the product thickness as a function of $t$ were carried out at $180^{\circ} \mathrm{C}$ : by Eq. (1), $k=4.7 \cdot 10^{-12}\left(\right.$ eq $\mathrm{cm}^{-1} \mathrm{sec}^{-1}$ ) was obtained (for $\mathrm{AgTlI}_{2}$ formation, in this case, $v=320 \mathrm{~cm}^{3} / \mathrm{eq}$ ).

(III) Reaction AgTlI ${ }_{2}+\mathrm{TlI}$. Marker experiments carried out on the couples $\mathrm{AgTlI}_{2} \mid \mathrm{TII}$ 


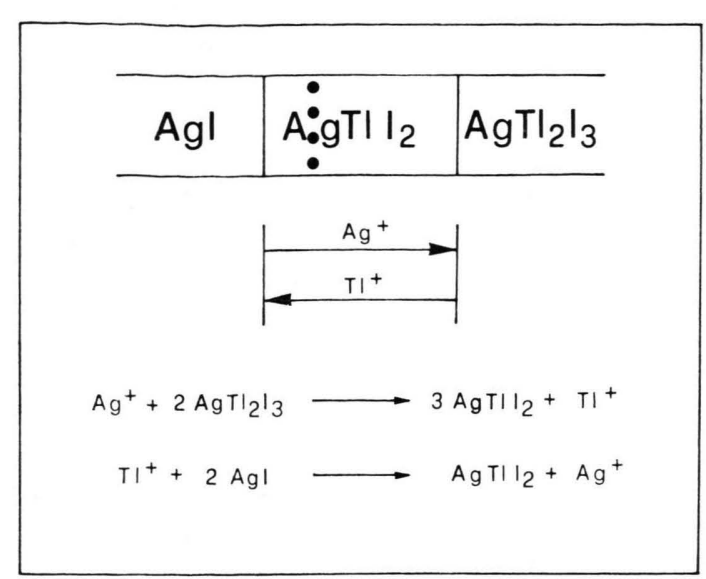

Fig. 4. Scheme for reaction (II) mechanism.

at $180^{\circ} \mathrm{C}$ once again showed the marker inside the white product $\left(\mathrm{AgTl}_{2} \mathrm{I}_{3}\right)$ layer. The thickness of the latter, however, even after very long reaction times $(130 \mu \mathrm{m}$ in $360 \mathrm{~h})$ was not sufficient to allow an accurate estimate of the marker position. Anyhow, the following cation counter-diffusion mechanism can be reasonably proposed: at the $\mathrm{AgTl}_{2} \mathrm{I}_{3} \mid \mathrm{TII}$ interface

$$
\mathrm{Ag}^{+}+3 \mathrm{TlI} \rightarrow \mathrm{AgTl}_{2} \mathrm{I}_{3}+\mathrm{Tl}^{+}
$$

at the $\mathrm{AgTlI}_{2} \mid \mathrm{AgTl}_{2} \mathrm{I}_{3}$ interface

$$
\mathrm{Tl}^{+}+3 \mathrm{AgTlI}_{2} \rightarrow 2 \mathrm{AgTl}_{2} \mathrm{I}_{3}+\mathrm{Ag}^{+} .
$$

Also for this reaction, measurements of the product layer thickness as a function of $t$ were carried out at $180^{\circ} \mathrm{C}$, yielding $k=0.2 \cdot 10^{-12} \mathrm{eq}^{-1} \mathrm{sec}^{-1}$ (for $\mathrm{AgTl}_{2} \mathrm{I}_{3}$ formation, $v=374 \mathrm{~cm}^{3} / \mathrm{eq}$ ).

\section{b) Transport Numbers and Conductivity Measurements}

For the determination of the transport numbers of $\mathrm{Ag}^{+}$and $\mathrm{Tl}^{+}$in $\mathrm{AgTlI}_{2}$, the pellet sequence

$$
+\mathrm{Ag}|\mathrm{AgI}| \mathrm{AgTlI}_{2}\left|\mathrm{AgTlI}_{2}\right| \mathrm{AgTlI}_{2}|\mathrm{AgI}| \mathrm{Ag}-
$$

was used *.
Table 1 reports the mass variations $(\mathrm{mg})$ of each pellet for three different runs at $180^{\circ} \mathrm{C}$. The following transport number values were then obtained:

$$
t_{\mathrm{Ag}^{+}}=0.97_{5}, \quad t_{\mathrm{TI}^{+}}=0.02_{5} .
$$

As regards $\mathrm{AgTl}_{2} \mathrm{I}_{3}$ the measurements (carried out at the same temperature on a similar pellet sequence) yielded less accurate results owing to the disturbing reaction of $\mathrm{AgI}$ with $\mathrm{AgTl}_{2} \mathrm{I}_{3}$. It was possible, however, by means of a proper procedure to minimize this effect and to state that $t_{\mathrm{Ag}^{+}}$and $t_{\mathrm{TI}^{+}}$in $\mathrm{AgTl}_{2} \mathrm{I}_{3}$ are of the same order of magnitude as in $\mathrm{AgTlI}_{2}$.

The electrical conductivity $(\sigma)$ measurements on $\mathrm{AgTlI}_{2}$ were made in the temperature range $150-$ $200{ }^{\circ} \mathrm{C}$. In order to reduce the contact resistance, pellets of a $\mathrm{Ag}+\mathrm{AgTlI}_{2}$ mixture were used as electrodes.

The $\log \sigma$ values show a linear dependence on $1 / T$ according to the equation

$$
\log \sigma=3.5-14,451 / 4.576 T .
$$

It should be noted that the slopes given by the Eqs. (2), (3), and (4) are practically the same.

For $\mathrm{AgTl}_{2} \mathrm{I}_{3}$ at $180^{\circ} \mathrm{C}$ the value $\sigma=5.0 \cdot 10^{-5}$ $\left(\mathrm{ohm}^{-1} \mathrm{~cm}^{-1}\right)$ was obtained.

\section{c) Further Remarks}

The marker experiments and the transport number determinations on $\mathrm{Ag}^{+}$and $\mathrm{Tl}^{+}$in $\mathrm{AgTlI}_{2}$ and $\mathrm{AgTl}_{2} \mathrm{I}_{3}$ allow to conclude that the governing mechanism of the three reactions is the cation counterdiffusion and that the rate-determining step is the diffusion of $\mathrm{Tl}^{+}$in the product layer.

The rate constants for the reactions (I), (II) and (III) can be calculated by means of the thermodynamic theory proposed by Wagner ${ }^{12}$ and developed by Schmalzried ${ }^{6}$. In the present case, the equation proposed by the latter author for cation

\begin{tabular}{lllllll}
\hline $\begin{array}{l}\text { Charge } \\
\text { flowed } \\
\text { (coul.) }\end{array}$ & $+\mathrm{Ag}$ & $\mathrm{AgI}$ & $\mathrm{AgTlI}_{2}$ & $\mathrm{AgTII}_{2}$ & $\mathrm{AgTII}_{2}$ & $\mathrm{AgI} \mid \mathrm{Ag}-$ \\
\hline 36 & -40.10 & 0 & -0.70 & -0.30 & 0 & +41.10 \\
60.8 & -67.80 & 0 & -1.15 & -1.15 & +0.05 & +69.05 \\
36 & -40.00 & 0 & -0.75 & -0.05 & -0.05 & +40.70 \\
\hline
\end{tabular}

Table 1. Transport number determinations of $\mathrm{Ag}^{+}$and $\mathrm{Tl}^{+}$on $\mathrm{AgTII}_{2}$ according to Tubandt. Mass variation (mg) at $180^{\circ} \mathrm{C}$.

* $\mathrm{AgTII}_{2}$ and $\mathrm{AgTl}_{2} \mathrm{I}_{3}$ show no electronic conductivity and have been classified as silver ion conductors ${ }^{7}$; the AgI pellets were inserted in order to avoid dendrite formation ${ }^{11}$. 
counter-diffusion is of the form

$$
k=\gamma D_{\mathrm{Tl}^{+}} c_{\mathrm{Tl}^{+}}\left|\Delta G^{0}\right| / R T
$$

were $\gamma=$ numerical factor whose value depends on the reaction mechanism; $D_{\mathrm{Tl}^{+}}=$self-diffusion coefficient of $\mathrm{Tl}^{+}$in the reaction layer ${ }^{* *} ; c_{\mathrm{Tl}^{+}}=$equivalent concentration of $\mathrm{Tl}^{+}$in the reaction product; $\Delta G^{0}=$ molar standard free energy of the reaction.

The $\Delta G^{0}$ values of these reactions were estimated by the Wagner method ${ }^{13}$ applied to the AgI-TlI phase diagram. These values, necessarily obtained only for particular temperatures, were used at $180^{\circ} \mathrm{C}$.
In spite of the approximations involved, the calculated values are in satisfactory agreement with those directly obtained at $180^{\circ}$ by kinetics measurements (Table 2).

Finally, the fact that reaction (III) is much slower than reaction (II) might reasonably account for the observed absence of appreciable amounts of $\mathrm{AgTl}_{2} \mathrm{I}_{3}$ in reaction (I).

The authors are indebted to Dr. G. Chiodelli for having kindly carried out the conductivity measurements.

Table 2. Comparison of $k_{\text {calc }}$ and $k_{\exp }\left(\mathrm{eq} \mathrm{cm}^{-1} \mathrm{sec}^{-1}\right)$ at $180^{\circ} \mathrm{C}$ for reactions (I), (II) and (III).

\begin{tabular}{lllllll}
\hline Reaction & $\gamma$ & $\begin{array}{l}D_{\mathrm{Tl}^{+}} \cdot 10^{10} \\
\left(\mathrm{~cm}^{2} \mathrm{sec}^{-1}\right)\end{array}$ & $\begin{array}{c}c \mathrm{Tl}^{+} \cdot 10^{2} \\
\left(\mathrm{eq} \mathrm{cm}^{-3}\right)\end{array}$ & $\begin{array}{l}\Delta G^{0} \\
\left(\mathrm{kcal} \mathrm{mole}^{-1}\right)\end{array}$ & $\begin{array}{c}k_{\mathrm{calc}} \cdot 10^{12} \\
\left(\mathrm{eq} \mathrm{cm}^{-1} \mathrm{sec}^{-1}\right)\end{array}$ & $\begin{array}{l}k_{\mathrm{exp}} \cdot 10^{12} \\
\left(\mathrm{eq}^{-1} \mathrm{sec}^{-1}\right)\end{array}$ \\
\hline (I) & 2 & 2.7 & 1.25 & $-1\left(202^{\circ} \mathrm{C}\right)$ & 7.5 & 9.6 \\
(II) & 4 & 2.7 & 1.25 & $-0.3\left(175^{\circ} \mathrm{C}\right)$ & 4.5 & 4.7 \\
(III) & 1.5 & 0.3 & 1.60 & $-0.2\left(175^{\circ} \mathrm{C}\right)$ & 0.2 & 0.2 \\
\hline
\end{tabular}

** The $D_{\mathrm{Tl}+}$ values at $180^{\circ}$ have been evaluated by the Nernst-Einstein equation assuming a unitarian correlation factor:

$$
D_{\mathrm{Tl}^{+}}=\left(R T / F^{2}\right) t_{\mathrm{Tl}^{+}}\left(\sigma / c_{\mathrm{Tl}^{+}}\right) .
$$

1 J. N. Bradley and P. D. Greene, Trans. Faraday Soc. 63, 424 [1967].

2 J. N. Bradley and P. D. Greene, Trans. Faraday Soc. 63, 1023 [1967].

3 L. G. Berg and I. N. Lepeshkov, Izv. Sektora Fiz-Khim. Anal. Inst. Obshch. Neorg. Khim., Akad. Nauk SSSR, 15, 148 [1947].

4 G. A. Samara, L. C. Walters, and D. A. Northrop, J. Phys. Chem. Solids 28, 1875 [1967].

5 L. Helmholz, Z. Kristallogr. 95, 129 [1936].
${ }^{6}$ H. Schmalzried, "Point Defects in Ternary Ionic Crystals" in Progress in Solid State Chemistry, Pergamon Press, London 1965, Vol. II, p. 265.

7 A. Schiraldi, A. Magistris, and E. Pezzati, Z. Naturforsch. 29 a, 782 [1974].

8 G. Flor, V. Massarotti, and R. Riccardi, Z. Naturforsch. 29 a, 503 [1974].

9 H. Hirsch, J. Chem. Soc. 1963, 1318. - P. Messien, Bull. Soc. Roy. Sci. Liège, 38, 490 [1969].

10 H. Schmalzried, Z. physik. Chem. N. F. 33, 111 [1962].

11 W. Jost, Diffusion in Solids, Liquids, Gases. Acad. Press Inc. New York 1952, p. 182.

12 C. Wagner, Z. phys. Chem. B 34, 309 [1936].

13 C. Wagner, Acta Metallurg. 6, 309 [1958]. 